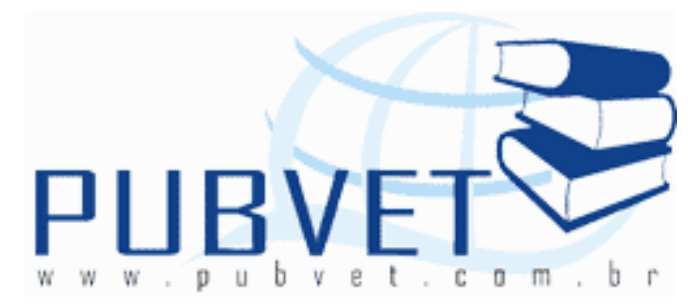

PUBVET, Publicações em Medicina Veterinária e Zootecnia.

\title{
Principais problemas locomotores na avicultura industrial
}

Marília Nogueira da Silva Fernandes ${ }^{1}$

${ }^{1}$ Doutoranda em Zootecnia, Departamento de Zootecnia, Escola de Veterinária, UFMG, Brasil. E-mail: marilia.fernandes@gmail.com

\section{Resumo}

Os problemas locomotores podem estar associados às características genéticas dos frangos, que apresentam crescimento e acúmulo do tecido muscular muito rápido, com o tecido ósseo se desenvolvendo a uma velocidade menor. A dieta é um importante componente que influencia o desenvolvimento do osso. Entre os fatores nutricionais, os mais estudados, por estarem relacionados com os problemas locomotores, são: o cálcio, o fósforo, a relação cálcio: fósforo e a vitamina D. Esta revisão teve como objetivo abordar sobre os seguintes problemas locomotores presentes na avicultura industrial: a condrodisplasia, o raquitismo, a osteomalacia, a osteodistrofia fibrosa, a osteoporose, a osteocondrose, a espondilolistese e a osteopenia. 
FERNANDES, M.N.S. Principais problemas locomotores na avicultura industrial. PUBVET, Londrina, V. 6, N. 18, Ed. 205, Art. 1369, 2012.

\title{
Locomotor problems in aviculture
}

\begin{abstract}
Locomotor problems may be associated with genetic characteristics of chickens, which have accumulation and increase of the muscle tissue very fast, with bone tissue developing at a lower speed. Diet is an important component which influences the development of bone. Among those nutritional factors, the most widely studied, since they are related to leg problems, are: calcium, phosphorus, the relation calcium: phosphorus and vitamin D. This review aims address about locomotors issues present in aviculture: chondrodysplasia, rickets, osteomalacia, fibrous osteoarthritis, osteoporosis, osteochondrosis, spondylolisthesis and osteopenia.
\end{abstract}

\section{INTRODUÇÃO}

A seleção genética constante e a melhoria na nutrição vêm fazendo com que o frango de corte atinja o peso de abate cada vez mais cedo. Essa taxa de crescimento precoce é acompanhada por numerosos problemas, tais como: aumento nas taxas de mortalidade, alta incidência de doenças metabólicas e desordens no sistema locomotor (Chambers, 1995).

$\mathrm{Na}$ comparação entre linhagens selecionadas e controle, observam-se diferenças significativas quanto à mortalidade e a alta incidência de deformidades de pernas associada à seleção para aumento do peso corporal (Havenstein et al., 1994a).

O desenvolvimento de programas práticos que reduzam estes problemas sem afetar negativamente a eficiência da produção é um constante desafio para a avicultura industrial. Há evidencias de que vários tipos de problemas de perna são herdados e são responsivos à seleção genética (Emmerson et al., 1991). As anormalidades de locomoção são endêmicas e comumente referidas como fraqueza de pernas, com incidência e severidade variando entre as linhagens (Zubair \& Lesson, 1996). A locomoção é parte central das atividades vitais que levam saúde e bem estar às aves, não deveriam ser prejudicadas pelas 
FERNANDES, M.N.S. Principais problemas locomotores na avicultura industrial. PUBVET, Londrina, V. 6, N. 18, Ed. 205, Art. 1369, 2012.

disfunções estruturais com conseqüente desconforto e dor (Freitas \& Nunes, 2001).

Uma categoria mais geral de problemas de perna consiste de anormalidades estruturais que levam à distorção de ossos longos e às deformidades rotacionais e angulares, como: espondilolistese, discondroplasia tibial, condrodistrofia, entre outros.

O objetivo desta revisão de literatura foi abordar sobre os seguintes problemas ósseos na avicultura industrial: a condrodisplasia, o raquitismo, a osteomalacia, a osteodistrofia fibrosa, a osteoporose, a osteocondrose, a espondilolistese, e a osteopenia.

\section{REVISÃO DE LITERATURA}

\section{Tecido ósseo}

O tecido ósseo possui vasos sangüíneos, nervos e tem capacidade de se regenerar quando sofre alguma injuria ou é acometido por processos patológicos. Está intimamente relacionado com o crescimento do animal, sofrendo adaptações constantes quanto à sua constituição, podendo ser hipertrofiado quando mais exigido, ou atrofiado quando em desuso (Biewener \& Bertram, 1994).

Para atender as necessidades de crescimento do organismo os ossos sofrem processo de modelagem, que representa o alongamento longitudinal e do diâmetro. A remodelagem é o termo usado para descrever processos de reabsorção e formação de tecido mineralizado que mantém a massa óssea e a morfologia nas aves adultas (Tardin, 1995).

As propriedades químicas, físicas e biomecânicas têm sido utilizadas como parâmetros para avaliação da qualidade óssea (Leterrier \& Nys, 1992). O osso é um tecido dinâmico e complexo, influenciado por fatores fisiológicos, nutricionais e físicos (Brewenwer \& Betram, 1994). 
FERNANDES, M.N.S. Principais problemas locomotores na avicultura industrial. PUBVET, Londrina, V. 6, N. 18, Ed. 205, Art. 1369, 2012.

\section{Matriz extracelular}

O osso é constituído de uma matriz orgânica mineralizada com diversos elementos celulares imersos. A matriz extracelular é composta por colágeno em sua maior parte e pela substância fundamental.

O colágeno é encontrado em todos os tecidos do corpo sendo uma proteína fibrosa sintetizada por fibroblastos e células relacionadas, tais como os condroblastos da cartilagem e os osteoblastos do osso (Swenson, 1988).

$\mathrm{Na}$ cartilagem há o predomínio do colágeno fibrilar tipo II, enquanto que o osso é composto de colágeno fibrilar tipo I, podendo os dois tipos ser encontrados em tecidos sujeitos ao estresse de compressão e tensão. Os colágenos fibrilares tipo I e II formam uma rede fibrilar na matriz extracelular que são estabilizadas pela formação de ligações cruzadas intra e inter moleculares por condensação de resíduos de aminoácidos (Velleman, 2000). Alterações na síntese ou na organização das fibras do colágeno afetam as propriedades de resistência do osso. A tenacidade e a resistência do osso diminuem significativamente com a desnaturação do colágeno (Currey, 2003a).

A substância fundamental fica dispersa entre as fibras de colágeno do tecido, é contínua com o líquido intersticial e apresenta vários graus de condensação, sendo conhecida como o componente amorfo extracelular e interfibrilar de todo tecido conjuntivo. Consistem em polissacarídeos protéicos (sulfato de condroitina), glicoproteínas, proteína não estrutural, eletrólitos e água (Swenson, 1988).

Os proteoglicanos são macromoléculas compostas por uma proteína central com carboidratos ligados covalentemente a ela (Velleman, 2000). São carregadas negativamente, amorfas, sulfatadas e se caracterizam por formar géis capazes de reter grandes quantidades de água em suas matrizes. Importante na formação, estrutura e função biológica da cartilagem (De Robertis Jr, 2003). 
FERNANDES, M.N.S. Principais problemas locomotores na avicultura industrial. PUBVET, Londrina, V. 6, N. 18, Ed. 205, Art. 1369, 2012.

\section{Células do tecido ósseo}

O tecido ósseo é composto de quatro tipos de células: os osteoblastos, os osteoclastos, os osteócitos e as células osteoprogenitoras ou osteogênicas. Os osteoblastos, osteócitos e as células osteoprogenitoras são os responsáveis pela formação do tecido ósseo, os osteoclastos pela reabsorção óssea (Pizauro Jr, 2002).

\section{Células osteoprogenitoras}

As células osteoprogenitoras são células em repouso ou de reserva que podem ser estimuladas para se transformar em osteoblastos e produzir matriz óssea. Compõe a camada mais interna do periósteo, as células endósteas de revestimentos das cavidades medulares e as células de revestimento dos canais de Havers e de Volkmann (Ross \& Rowrel, 1993).

\section{Osteoblastos}

Os osteoblastos são células diferenciadas que produzem a matriz óssea, secretando colágeno e a substância fundamental, que constituem o osteóide e situam-se em aposição ao osso em formação. Participam da calcificação da matriz, através da secreção de pequenas vesículas ricas em fosfatase alcalina para o interior desta, somente durante o período em que a célula está produzindo a matriz óssea (Ross \& Rowrel, 1993).

A fosfatase alcalina cliva 0 pirofosfato removendo a sua influência estabilizadora e aumentando a concentração local de fosfato, promovendo a cristalização. Durante o crescimento ósseo e remodelagem do osso adulto, os osteoblastos secretam vesículas ricas em cálcio para o osteóide em mineralização (Jonhson, 2000).

\section{Osteócitos}

Os osteócitos são as células ósseas maduras e correspondem a um osteoblasto transformado. Responsáveis pela manutenção da matriz óssea, sintetizando e reabsorvendo-a até certo ponto. Cada osteócito ocupa um espaço ou lacuna 
FERNANDES, M.N.S. Principais problemas locomotores na avicultura industrial. PUBVET, Londrina, V. 6, N. 18, Ed. 205, Art. 1369, 2012.

que se amolda à sua forma lenticular. Estendem seus prolongamentos citoplasmáticos através de canalículos situados na matriz óssea para entrar em contato com prolongamentos de células vizinhas (Pizauro Jr., 2002).

\section{Osteoclastos}

Os osteoclastos São grandes células que surgem pela fusão de células mononucleadas e podem ter até 50 núcleos. Os precursores dos osteoclastos se originam na medula óssea e migram pela circulação, a partir do timo e outros tecidos retículo-endoteliais, para os sítios do osso destinados à reabsorção óssea. Os precursores são atraídos para os sítios de reabsorção óssea por produtos parcialmente degradados do osteóide (Jonhson, 2000).

\section{Formação do tecido ósseo}

Há dois processos básicos de formação do tecido ósseo: a ossificação endocondral e a intramembranosa. O desenvolvimento do osso é classificado como endocondral, no caso de um modelo de cartilagem servir de precursor do tecido ósseo que será formado. E, intramembranoso, se o osso for formado sem a intervenção de um precursor cartilaginoso (Pizauro Jr, 2002).

\section{Ossificação endocondral}

O processo de ossificação endocondral é o responsável pelo crescimento da maioria dos ossos do esqueleto e aqueles da base do crânio. Caracterizado por tecido ósseo que é depositado em uma rede de cartilagem calcificada. Em circunstâncias normais, a calcificação ocorre no disco epifisário. Esse processo é responsável pelo desenvolvimento em comprimento e aumento do esqueleto durante o crescimento (Pizauro Jr, 2002).

\section{Ossificação intramembranosa}

Nesse processo há um centro de ossificação que é circundado pelos osteoblastos para a deposição de osso. O processo progride do centro para a periferia do osso, produzindo uma rede de trabéculas ósseas que se espessam 
FERNANDES, M.N.S. Principais problemas locomotores na avicultura industrial. PUBVET, Londrina, V. 6, N. 18, Ed. 205, Art. 1369, 2012.

e fundem-se formando uma lamina óssea que é separada dos ossos adjacentes por tecido fibroso persistente. O aumento na circunferência resulta da ossificação do tecido fibroso circunjacente, que continua a crescer até o osso atingir seu tamanho definitivo (Guyton, 1997).

\section{Constituintes minerais do osso}

O osso é constituído aproximadamente por $70 \%$ de minerais, $20 \%$ de matriz orgânica e $10 \%$ de água, o diferenciando de outros tecidos conjuntivos menos rígidos. A matriz mineral ou inorgânica é formada predominantemente por cálcio ( $\mathrm{Ca}$ ) e fósforo $(\mathrm{P})$ na forma de cristais de hidroxiapatita $\left(\mathrm{Ca}_{3}\left(\mathrm{PO}_{4}\right)_{2}\right)$, sendo responsável pelas propriedades de rigidez e resistência à compressão (Rath et al., 2000).

Além da hidroxiapatita, que compõe $80 \%$ da fase mineral, outros minerais também são encontrados, o carbonato de cálcio $\left(\mathrm{CaCO}_{3}\right)$ e o fosfato de magnésio $\left(\mathrm{Mg}\left(\mathrm{PO}_{4}\right)_{2}\right)$ (Field, 2000).

Os constituintes minerais do osso são trocados constantemente com os constituintes do plasma. A desmineralização do osso ocorre quando a ingestão de minerais é inadequada ou quando sua perda é excessiva. A ossificação envolve a precipitação dos sais do osso na matriz, por meio de um equilíbrio

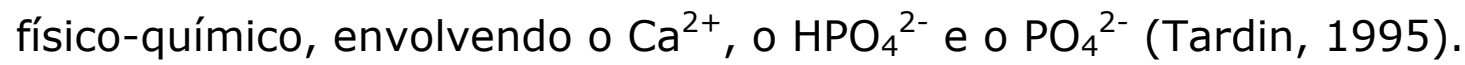

\section{Problemas locomotores na avicultura industrial}

Os frangos de corte, quando comparados a outros animais, têm as maiores taxas de formação óssea, sendo muito sensíveis às manipulações nutricionais e bioquímicas que afetam os processos de crescimento e desenvolvimento, principalmente, dos ossos longos (Bain \& Watkins, 1993).

As aves que são acometidas por problemas de perna apresentam dificuldade de locomoção, sentem dores, desconforto físico com restrições de comportamento tendo sua taxa de crescimento reduzida (Yalçin et al., 1998). Além de causarem deformidades ósseas e aumentarem o risco de fraturas e 
FERNANDES, M.N.S. Principais problemas locomotores na avicultura industrial. PUBVET, Londrina, V. 6, N. 18, Ed. 205, Art. 1369, 2012.

infeç̧ões, diminuem o desempenho no crescimento, aumentam a mortalidade e as condenações de carcaça (Rath et al., 1999).

O osso demora mais tempo para atingir a maturidade do que gasta para crescer, ou seja, o desenvolvimento e a maturidade do osso não acompanham a taxa de crescimento, resultando em excesso de peso sobre ossos imaturos, predispondo a deformidade e fragilidade dos mesmos (Rath et al., 2000).

Embora vários fatores contribuam para a incidência de problemas ósseos em aves, a dieta destaca-se como importante componente que influencia sobre o desenvolvimento do osso, vários nutrientes afetam diretamente o desenvolvimento ósseo. Entre os fatores nutricionais, alguns têm sido mais estudados por estarem diretamente relacionados com as anomalias ósseas, como: a relação cálcio e fósforo, a vitamina D e o ácido ascórbico (Praul et al., 2000).

Os problemas de pernas podem estar associados às características genéticas dos frangos, que apresentam crescimento e acúmulo de tecido muscular muito rápido, com o tecido ósseo se desenvolvendo a uma velocidade menor (Silva et al., 2001).

Nos frangos de corte, o crescimento acelerado dos ossos não permite que ocorra uma mineralização adequada, sendo que esses ossos mais imaturos apresentam maior porosidade e menor densidade (Williamns et al., 2004).

\section{Categorias de problemas ósseos}

A categorização dos problemas ósseos é muitas vezes difícil e arbitraria. As classificações recentes são com base na patogênese (Riddell, 1992).

A categorização apresentada é uma classificação inicial baseada na idade e tipo de aves afetadas tendendo a agrupar as condições de sua etiopatogenia. As patologias comumente encontradas em cada categoria são um indicativo da genética e estresse da produção sobre o esqueleto. As categorias são:

1. Aves jovens selecionadas para o crescimento rápido - comumente afetadas com distúrbios do crescimento ósseo. 
FERNANDES, M.N.S. Principais problemas locomotores na avicultura industrial. PUBVET, Londrina, V. 6, N. 18, Ed. 205, Art. 1369, 2012.

Distúrbios que ocorrem durante o crescimento ósseo são de natureza do próprio desenvolvimento ou metabólica e resultam em patologias da placa de crescimento ou anormalidades na modelagem óssea. Condições como: deformidade angular e torcional, discondroplasia, raquitismo, osteocondrose e condrodistrofia.

2. Aves jovens e adultas (matriz pesada/ galos) - comumente afetadas com problemas degenerativos da articulação.

A artrose em matrizes pesada é causada por alterações degenerativas na cartilagem articular. As lesões osteocondróticas são comuns no complexo epifeseal - articular. Essas lesões levam a degeneração da cartilagem articular com a formação de erosões, bordas de cartilagem e corpos osteocartilaginosos. As lesões geralmente ocorrem no trochanter do fêmur. A degeneração progressiva da cartilagem articular resulta em osteonecrose e pode manifestar com uma perda do desempenho reprodutivo.

3. Galinhas em postura - comumente afetadas com fragilidade óssea. A fragilidade óssea em poedeiras é freqüentemente causada por osteoporose, uma desordem metabólica. As poedeiras possuem dois tipos de ossos, cortical/ trabecular (estrutural) e/ ou medular. O osso estrutural mantém a integridade física do esqueleto e o osso medular serve como uma reserva de cálcio para a formação da casca do ovo. A redução na quantidade de osso estrutural enfraquece o esqueleto, culminando em osteoporose. A osteoporose é observada em praticamente todas as poedeiras, mesmo com uma adequada suplementação mineral, mas a severidade pode variar acentuadamente (Thurp, 1994).

\section{Condrodisplasia}

A condrodisplasia é definida como uma desordem generalizada das placas de crescimento dos ossos longos, de tal forma que o crescimento linear é prejudicado durante a mineralização e a ossificação endocondral permanece 
FERNANDES, M.N.S. Principais problemas locomotores na avicultura industrial. PUBVET, Londrina, V. 6, N. 18, Ed. 205, Art. 1369, 2012.

normal. Os ossos que crescem mais rapidamente, são os mais severamente afetados, parecem encurtados e grossos. Além disso, secundariamente, tornam-se inclinados (Wise, 1975).

Os sinais mais característicos condrodisplasia estão nas articulações do jarrete, as quais são aparentemente alargadas e com nódulos. As deformidades varus ou valgus do osso tarsometatarso freqüentemente desenvolve e, às vezes, torna-se tão severa que o tendão gastrocnêmio "desliza" da fossa intercondilar até a extremidade distal do osso tibiotársico (Wise, 1975).

Condrodisplasia não é o nome usual dado à condição patológica descrita acima. Para alguns é descrita como perose, para outros como deslizamento do tendão gastrocnêmio, para outros implica em um estado de deficiência de colina ou manganês, ou para outro grupo, como um termo menos específico para aplicar a todas as condições condrodistroficas generalizadas (Nair \& Watson, 1972).

Está bem estabelecido que as deficiências de uma lista de nutrientes podem causar condrodisplasia generalizada. Estas incluem o manganês, a colina, a biotina, o ácido nicotínico, o ácido fólico, o zinco e a piridoxina (Gries \& Scott, 1972). Hoje, esses estados de deficiência são extremamente raros nas condições de campo.

Segundo Wise, Jennings \& Bostock (1973), a lesão primaria da condrodisplasia reside na zona de proliferação da placa de crescimento e consiste, essencialmente, de uma baixa taxa mitótica de condrócitos em proliferação. $E$, não há diferenças histopatológicas nas placas de crescimento entre as diferentes deficiências nutricionais.

\section{Osteocondrose}

Discondroplasia é o termo mais freqüentemente usado para descrever osteocondrose da cartilagem epifiseal em aves. O termo osteocondrose deve ser usado para se referir a todos os distúrbios de ossificação endocondral, sejam eles na cartilagem epifisiária - articular ou na cartilagem epifiseal. No entanto, quando a patologia primária for originária de um distúrbio da cartilagem, e todos os efeitos sobre os tecidos ossificados são secundários ao 
FERNANDES, M.N.S. Principais problemas locomotores na avicultura industrial. PUBVET, Londrina, V. 6, N. 18, Ed. 205, Art. 1369, 2012.

defeito da cartilagem, o termo discondroplasia passa a ser mais apropriado (Olsson, 1978).

A osteocondrose e a discondroplasia são distúrbios na ossificação endocondral e os termos têm sido utilizados como sinônimos (Hill et al., 1984). O termo osteocondrose também tem sido aplicado para lesões na cartilagem da placa de crescimento e confusão pode existir com a diferenciação de discondroplasia de osteocondrose (Ridell, 1992).

Osteocondrose é um distúrbio idiopático de ossificação endocondral e que ocorre nas extremidades ósseas que estavam crescendo normalmente. A condição pode ser encontrada na cartilagem epifiseal, na cartilagem hialina epifiseal ou no complexo epifiseal - articular (Duff, 1990a). Tecnicamente, discondroplasia é uma manifestação da osteocondrose, porém alguns patologistas de aves as consideram separadamente (Crespo \& Shivaprasad, 2003).

As lesões microscópicas de osteocondrose nas aves incluem vasos com trombose e oclusão tanto na zona de crescimento cartilaginosa e zona de proliferação epifisiária, estrias eosinofílicas, necrose da matriz, lagos de material amorfo e lágrimas distintas ou fendas na cartilagem (Riddell et al., 1983).

As lesões típicas da osteocondrose são pequenas fendas e outros distúrbios focais de ossificação endocondral que foram descritas na zona de crescimento das vértebras, fêmur, tíbio-tarso e tarso-meta-tarso, incluindo pequenos defeitos discondroplásticos que são atribuídos a um distúrbio vascular local (Duff, 1990a).

A nutrição e o processo de seleção genética podem afetar a incidência de osteocondrose. A relação Ca:P alterada e a deficiência de cisteína, homocisteína e do cobre, aumentam a incidência de osteocondrose (Farquharson \& Jefferies, 2000). 
FERNANDES, M.N.S. Principais problemas locomotores na avicultura industrial. PUBVET, Londrina, V. 6, N. 18, Ed. 205, Art. 1369, 2012.

\section{Espondilolistese}

A espondilolistese, conhecida na avicultura como Kinky back, acomete frangos de corte entre a $3^{a}$ e $6^{a}$ semanas de idade (Kelly, 1971). É considerada uma deformidade que afeta as vértebras torácicas de frangos de corte, mais freqüentemente a quarta vértebra torácica (Hogg, 1984), resultando em compressão da medula espinhal e dificuldade de movimentação, chegando à paralisia dos membros pélvicos.

A incidência da espondilolistese, que pode variar entre 2 a $10 \%$ em aviários comerciais, depende de três fatores principais: idade, taxa de crescimento e genética (Paixão et al., 2007).

A manifestação clínica mais comum é a paraplegia, com as aves apoiadas sobre a cauda ou sobre as articulações tibiotarsometatársicas com os pés suspensos no ar. Em casos avançados, as aves encontram-se em decúbito lateral. A morte nos casos de espondilolistese é conseqüência da desidratação e inanição devido à impossibilidade de acesso a água e ração (Wise, 1970).

Segundo Wise (1970), em granjas com espondilolistese clínica, observam-se casos subclínicos com apenas a manifestação de cladicação ocasional em algumas aves, embora na maioria dos casos subclínicos as aves apresentam-se completamente normais.

As causas mais prováveis da espondilolistese são ligamentos fracos ou ligação frágil do osso por causa da imaturidade óssea, e o elevado peso do músculo do peito. São componentes genéticos moderados (Julian, 1990).

\section{Raquitismo}

Raquitismo é definido como uma osteodistrofia generalizada, na qual a baixa mineralização é a principal característica patológica. A ocorrência de raquitismo é, na grande maioria dos casos, de origem nutricional, geralmente deficiência de vitamina D3 e/ou de fósforo disponível. Raramente, o raquitismo pode resultar de um problema metabólico no fígado ou nos rins, impedindo a vitamina D3 de ser convertida na sua forma fisiologicamente ativa, 
FERNANDES, M.N.S. Principais problemas locomotores na avicultura industrial. PUBVET, Londrina, V. 6, N. 18, Ed. 205, Art. 1369, 2012.

dihidroxicolecalciferol. O papel dessa vitamina é estimular a absorção de cálcio no intestino (Wise, 1975).

No raquitismo de origem nutricional, as duas principais causas são: as deficiências de cálcio e de fósforo. Conhecidos como raquitismo hipocalcêmico e raquitismo hipofosfatêmico, respectivamente.

No raquitismo hipocalcêmico, há o espessamento da placa epifisária do osso causado por acumulação da proliferação de condrócitos (Jande \& Dickson, 1980). Este processo é acompanhado por um aumento no comprimento dos vasos perfurantes da placa epifisária (Lacey \& Huffer, 1982). A aparência histológica descrita é típica da maioria dos casos de raquitismo no campo, sugerindo que o baixo cálcio no plasma é a causa mais provável.

No raquitismo hipofosfatemico, há a acumulação de condrócitos hipertrofiados. Nas duas formas de raquitismo, hipocalcêmico e hipofosfatemico, existe um decréscimo na quantidade de cartilagem calcificada (Lacey \& Huffer, 1982). Um desequilíbrio na relação $\mathrm{Ca}: \mathrm{P}$ é fundamental para o desenvolvimento do raquitismo. Uma dieta contendo altos níveis de fósforo tem um efeito semelhante ao de uma dieta com baixa concentração de cálcio. Concentrações marginais de cálcio na dieta não causam raquitismo nas aves, mas pode aumentar a incidência e severidade da discondroplasia (Leach, 1982).

A deficiência de vitamina D3 provoca raquitismo por causa do baixo cálcio no plasma, associado com baixo peso corporal, baixas concentrações plasmáticas de fosfato inorgânico e elevada fosfatase alcalina (Jande \& Dickson, 1980). Com a baixa concentração de vitamina D3 na dieta, podem ocorrer algumas alterações leves de raquitismo no tíbio-tarso (Thorp et al., 1991).

O raquitismo é caracterizado por alterações na placa epifisária de crescimento, onde a zona de hipertrofia está alongada e com desorganização da arquitetura das colunas celulares. A calcificação é retardada ou ausente, a vascularização é irregular através de canais defeituosos. A camada esponjosa das metáfises mostra barra de cartilagem não calcificada (Mechica, 1999). 
FERNANDES, M.N.S. Principais problemas locomotores na avicultura industrial. PUBVET, Londrina, V. 6, N. 18, Ed. 205, Art. 1369, 2012.

\section{Osteodistrofia fibrosa}

Osteodistrofia fibrosa é uma patologia metabólica do osso que ocorre em conseqüência da ingestão de dietas deficientes em cálcio e altas concentrações de fósforo. Caracteriza-se por hiperparatiroidismo, aumento generalizado da reabsorção óssea e substituição por tecido fibroso. Em conseqüência do desequilíbrio da relação $\mathrm{Ca}: \mathrm{P}$ da dieta, geralmente devido à altas concentrações de fósforo, há hiperfosfatemia e estimulo das paratireóides (hiperparatiroidismo nutricional), aumento na secreção do paratormônio, resultando em reabsorção óssea para elevar a calcemia. Histologicamente observa-se severa osteopenia, caracterizada pela presença de poucas e finas trabéculas ósseas, ao redor das quais osteoblastos agrupados e numerosos osteoclastos. No espaço entre as trabéculas, há abundante tecido fibroso e osteoclastos agrupados, indicando uma intensa reabsorção óssea (Méndez, 2001).

\section{Fragilidade óssea - osteoporose, osteopenia e osteomalacia}

Os problemas ósseos causados pela diminuição na mineralização do osso estrutural são conhecidos como fragilidade óssea. Entre essas desordens estão à osteoporose, a osteopenia e a osteomalacia.

\section{Osteoporose}

A osteoporose em poedeiras é definida como um decréscimo da mineralização normal do osso estrutural, resultando em aumento da fragilidade e susceptibilidade a fratura. Primeiramente foi descrito em galinhas criadas em gaiolas que tinham ossos frágeis e eram incapazes de ficar "em pé", mas dispostas a comer e beber (Couch, 1955). A condição foi chamada de "fadiga de gaiola".

A osteoporose ainda é a doença óssea mais significante das galinhas poedeiras criadas em gaiolas. A fragilidade óssea é responsável por mais de $30 \%$ das fraturas durante toda a vida das criações comerciais, e a incidência pode 
FERNANDES, M.N.S. Principais problemas locomotores na avicultura industrial. PUBVET, Londrina, V. 6, N. 18, Ed. 205, Art. 1369, 2012.

ultrapassar 90\% durante a "pega", o transporte e o processamento (Whitehead \& Fleming, 2000).

A osteoporose em poedeiras é uma condição que envolve a perda progressiva do osso durante o período de postura. As poedeiras de alta produção podem torna-se deficientes em cálcio e desenvolver a osteoporose. Pode ser devido à incapacidade de metabolizar cálcio suficiente, ou por causa de uma dieta inadequada em cálcio, vitamina D3 ou fósforo (Whitehead et al., 2003).

Quando as poedeiras entram em produção, elas param de produzir o osso estrutural e produzem somente o osso medular. Se o osso medular está esgotado por causa da formação da casca do ovo e o cálcio não está disponível na dieta, a galinha começa a retirar o cálcio do osso cortical. O fósforo é exigido para reconstruir o osso medular uma vez que ambos, cálcio e fósforo, são retirados e substituídos durante o ciclo de formação da casca do ovo. As poedeiras criadas no chão ingerem o fósforo de suas excretas, então mais fósforo da dieta é exigido quando as galinhas estão em gaiolas. Os sinais e lesões são semelhantes à deficiência de cálcio. A deficiência de vitamina $D$ resulta em osteoporose em poedeiras, pois ela afeta o metabolismo do cálcio. Geralmente é observado como um problema no lote e pode ser acompanhado por baixa qualidade da casca do ovo (Julian, 2005).

\section{Osteopenia}

Uma freqüente patologia do esqueleto em galinhas poedeiras é a fratura do osso devido à osteopenia. Em um caso típico e severo os ossos longos e as vértebras fraturam e o externo e as costelas podem ser deformados. Podendo resultar em posterior paralisia através do colapso das vértebras torácicas e compressão da medula espinhal. Mais comumente, a osteopenia é uma conseqüência da osteoporose (Thorp, 2008).

\section{Osteomalacia}

Osteomalacia é uma doença óssea caracterizada pela diminuição da mineralização do osso cortical e trabecular, com acúmulo de tecido osteóide 
FERNANDES, M.N.S. Principais problemas locomotores na avicultura industrial. PUBVET, Londrina, V. 6, N. 18, Ed. 205, Art. 1369, 2012.

não mineralizado ou pouco mineralizado (Mechica, 1999). A osteomalacia pode ser uma conseqüência da suplementação inadequada de cálcio e/ ou de fósforo durante o crescimento (Thorp, 2008).

O quadro histológico da osteomalacia mostra alterações da mineralização no osso cortical e trabecular, com aumento da espessura osteóide (superior a 15 $\mu \mathrm{m})$, diminuição na velocidade de mineralização. Nos quadros dependentes de vitamina D há áreas com sinais de ação osteoclástica aumentada (Iannotti, 1990).

\section{CONSIDERAÇÕES FINAIS}

Os problemas locomotores, com vários graus de intensidade, são freqüentemente observados em frangos de corte. As anormalidades ósseas podem resultar em diminuição do bem-estar das aves e perdas econômicas devido à diminuição no desempenho produtivo, aumento na taxa de mortalidade e aumento das condenações de carcaça.

O rápido crescimento e as subseqüentes mudanças na fisiologia e biomecânica do esqueleto são fatores primários que contribuem para aumentar o aparecimento das lesões de pernas em frangos de corte.

A dieta influencia o desenvolvimento ósseo. O cálcio, o fósforo, a relação Ca:P e a vitamina $D$, são os fatores nutricionais mais relacionados com os problemas locomotores.

Os distúrbios de crescimento ósseo são as anormalidades ósseas que mais afetam a avicultura de corte.

As fragilidades ósseas são os problemas ósseos mais significantes na avicultura de postura atual em sistemas de criação em gaiolas.

\section{REFERÊNCIAS BIBLIOGRÁFICAS}

BAIN, S.D.; WATKINS, B.A. Local modulation of skeletal growth and bone modeling poultry.

Journal of Nutrition, v. 123, p. $317-322,1993$.

BIEWENER, A.A.; BERTRAM, J.E. Structural response of growing bone to exercise and disuse.

Journal of Apllied Physiology, v.76, n.2, p. 946 - 955, 1994. 
CHAMBERS, J.R. Advantages and disadvantages of genetic improvement of meat-type poultry and possible solutions. In: Simpósio Técnico de Matrizes de Corte, v. 1, Chapecó - SC.

Anais... Chapecó: Associação Catarinense de Avicultura, p. 120 - 131, 1995.

COLE, R.K.; AUSTIC, R.E. Hereditary uricemia and articular gout in chickens. Poultry Science, v. 59, p. $951-975,1980$.

COUCH, J.R. Cage layer fatigue. Feed Age, v.5, p. 55 - 57, 1955.

CRESPO, R.; SHIVAPRASAD, H.L. Developmental, metabolic and other noninfectious disorders. In: SAIF, Y.M.; BARNES, H.J.; GLISSON, J.R. et al. Diseases of Poultry. $11^{\text {th }}$ ed., Iowa State Press, Ames, p. 1055 - 1102, 2003.

CURREY, J.D. Role of collagen and other organics in the mechanical properties of bone.

Osteoporos Int., v.14, n.5, p. 29 - 36, $2003 a$.

DE ROBERTIS Jr, H.I.B. Biologia Celular e Molecular. $1^{\text {a }}$ Ed. Rio de Janeiro, Guanabara Koogan, p. $147-148,2003$.

DUFF, S.R.I. Diseases of the musculoskeletal system. In: JORDAN, F.T.W. Poultry Diseases. $3^{a}$ ed. Bailliere Tindall, London, p. 254 - 283, 1990a.

EMMERSON,D.A.; ANTHONY, N.B.; NESTOR, K.E.; et al. Genetic association of selection for increased leg muscle and increased shank diameter with body composition and walking ability. Poultry Science, v.70, n.4, p. 739 - 745, 1991.

FARQUHARSON, C.; JEFFERIES, D. Chondrocytes and longitudinal bone growth: The development of tibial dyschondroplasia. Poultry Science, v. 79, p. $994-1004,2000$.

FIELD, R.A. Ash and calcium as measures of bone in meat and bone mixtures. Meat Science, v.55, n.3, p. $255-264,2000$.

FREITAS, B.C.F.; NUNES, I.J. Fraqueza das pernas em frangos de corte: aspectos nutricionais. Cad. Tec. Vet. Zootec., v.34, p. 45 - 51, 2001.

GRIES, C.L.; SCOTT, M.L. The pathology of pyridoxine deficiency in chicks. Journal of Nutrition, v. 102, p. $1259-1268,1972$.

GUYTON, A.C. Tratado de Fisiologia Médica. 11 ed. Rio de Janeiro, Guanabara Koogan, 1997.

HILL, M.A.; RUTH, G.R.; HILLERY, H.D.; HANSGEN, D.C. Dyschondroplasias, including osteochondrosis, in boards between 25 and 169 days of age. American Journal of Veterinary Research, v.45, p. 903 - 916, 1984.

HAVENSTEIN, G.B.; FERKET, P.R.; SCHEIDELER, S.E.; LARSON, B.T. Growth, livability, and feed conversion of 1957 vs 1991 broilers when fed "typical" 1957 and 1991 broiler diets.

Poultry Science, v. 73, p. 1785 - 1794, 1994a.

HOGG, D.A. The distribuitionof pneumatisation in the skeleton of the adult domestic fowl. J. Anat., v. 138, p. $617-629,1984$.

IANNOTTI, J.P. Growth plate physiology and pathology. Orthopedic Clinics of North America, v. 21, p. $1-17,1990$. 
JOHNSON, L.R. Fundamentos de Fisiologia Médica. $2^{a}$ ed. Rio de Janeiro, Guanabara Koogan, p. $502-511,2000$.

JANDE, S.S.; DICKSON, I.R. Comparative histological study of the effects of high calcium diet and vitamin D supplements of epiphyseal plates of vitamin D deficient chicks. Acta Anatomica, v. 108, p. $169-173,1980$.

JULIAN, R.J. Avian Skeletal Disease Symposium. In: Annual Meeting of the American Association of Avian Pathologists/ AVMA, San Antonio, Texas, p. 1 - 11, 1990.

JULIAN, R.J. Production and growth related disorders and other metabolic diseases of poultry a review. The Veterinary Journal, v. 169, p. 350 - 369, 2005.

KELLY, W.R. Occurrence of spondylolisthesis ("Kinky Back") in broiler chicks in South Australia. Aust. Vet. J., v.47, p. 73, 1971.

LACEY, D.L.; HUFFER, W.E. Studies on the pathogenesis of avian rickets I. Changes in epiphyseal and metaphyseal vessels in hypocalcemic and hypophosphatemic rickets.

American Journal of Pathology, v. 109, p. 288 - 301, 1982.

LEACH, R.M. Nutrition and tibial dyschondroplasia. Western Poultry Disease Conference, University of California, Davis, p. 59 - 66, 1982.

LETERRIER, C.; NYS, Y. Composition, cortical structure and mechanical properties of chicken tibiotarsi: effect of growth rate. British Poultry Science, v. 33, n. 5, p. 925 - 939, 1992.

MECHICA, J.B. Raquitismo e Osteomalacia. Arq. Bras. Endocrinol. Metab., v. 43, n. 6, p. $457-466,1999$.

MÉNDEZ, M.C. Osteodistrofia fibrosa. In: Doenças de Ruminantes e Equinos. $2^{a}$ ed. São Paulo: Livraria Varela, p. $344-348,2001$.

NAIR, M.E.; WATSON, A.R.A. Leg weakness of poultry - a clinical and pathological characterization. Australian Veterinary Journal, v. 48, p. 645 - 655, 1972.

OLSSON, S.E. Osteochondrosis in domestic animals. Acta Radiologica Scandinavica, suppl. 358 , p. $9-12,1978$.

PAIXÃO, T.A.; RIBEIRO, B.R.C.; HOERR, F.J.; SANTOS, R.L. Espondilolistese em frangos de corte no Brasil. Arq. Bras. Med. Vet. Zootec., v.59, n.2, p. 523 - 526, 2007.

PIZAURO Jr, J.M. Estrutura e Função do Tecido Ósseo. In: MACARI, M.; FURLAN, R.L.; GONZALES, E. Fisiologia Aviária Aplicada a Frangos de Corte. Jaboticabal: FUNEP/UNESP, 2002.

PRAUL, C.A.; FORD, B.C.; GAY, C.V. et al. Gene expression and tibial discondroplasia. Poultry Science, v. 79, n. 7, p. $1009-1013,2000$.

RATH, N.C.; BALOG, J.M.; HUFF, G.R.; et al. Comparative differences in the composition and biomechanical properties of tibia of seven and seventy two week old male and female broiler breeder chickens. Poultry Science, v. 78, n. 8, p. 1232 - 1239, 1999.

RATH, N.C.; HUFF, G.R.; BALOG, J.M. Factors regulating bone maturity and strength in poultry. Poultry Science, v. 79, n. 7, p. $1024-1032,2000$. 
RIDDELL, C.; KING, M.W.; GUNASEKERA, K.R. Pathology of the skeleton and tendons of broiler chickens reared to roaster weights II. Normal chickens. Avian Diseases, v. 27, p. $980-991$, 1983.

RIDDELL, C. Non-infections skeletal disorders of poultry: an overview. In: WHITEHEAD, C.C. Bone biology and skeletal diseases in poultry. Carfax Publishing Company, Abingdon, p. 119 $145,1992$.

RIDDELL, C. Skeletal system. In: RIDDELL, C. Avian Histopathology. 2a ed. American Association of Avian Pathologists, Kennet Square, PA, p. 45 - 60, 1996.

ROSS, M.H.; ROWRELL, L.J. Histologia - Texto e Atlas. $2^{a}$ ed., São Paulo: Média Panamericana, 779 p., 1993.

SILVA, F.A.; MORAES, G.H.K.; RODRIGUES, A.C.P. ET AL. Efeitos do ácido L-glutâmico e da vitamina D3 nos fêmures e tibiotarsos de pintos de corte. Revista Brasileira de Zootecnia, v. 30, p. $2067-2077,2001$.

SWENSON, M.J. Fisiologia dos Animais Domésticos. 10a ed., Rio de Janeiro: Guanabara Koogan, 799 p., 1988.

TARDIN, A.C. Visão Nutricional dos Problemas Locomotores em Frangos de Corte. Conferência APINCO 1995 de Ciência e Tecnologia Avícolas. Campinas: SP, p. 71 - 83, 1995.

THORP, B.H.; WHITEHEAD, C.C.; RENNIE, J.S. Avian tibial dyschondroplasia: a comparison of the incidence and severity as assessed by gross examination and histopathology. Research in Veterinary Science, v. 51, p. $48-54,1991$.

THORP, B.H. Skeletal disordersin the fowl: a review. Avian Pathology, v. 23, p. $203-236$, 1994.

THORP, B.H. Diseases of the musculoskeletal system. In: Poultry Diseases. $6^{\text {th }}$ ed. British Library, p. $470-489,2008$.

VELLEMAN, S.G. The role of the extracellular matrix in skeletal development. Poultry Science, v.79, n. 7, p. $985-989,2000$.

WHITEHEAD, C.C.; FLEMING, R.H. Osteoporosis in cage layers. Poultry Science, v. 78, p. 1033 - 1041, 2000.

WHITEHEAD, C.C.; FLEMING, R.H.; JULIAN, R.J.; SORENSON, P. Skeletal problems associated with selection for increased production. In: MUIR, W.M.; AGGERY, S.E. Poultry Genetics, Breeding and Biotechnology. CABI Publishing, Wallingford, UK, p. 29 - 52, 2003.

WILLIANS, B.; WADDINGTON, D.; MURRAY, D.H. et al. Bone strength during growth: influence of growth rate on cortical porosity and mineralization. Calcif. Tissue Int., v.74, n.3, p. 236 245, 2004.

WISE, D.R. Spondylolisthesis ("King back") in broiler chicks. Res. Vet. Sci., v. 2, p. 447 $451,1970$.

WISE, D.R.; JENNINGS, A.R.; BOSTOCK, D.E. Perosis in Turkeys. Research in Veterinary Science, v. 14, p. $167-172,1973$. 
WISE, D.R. Skeletal abnormalities in table poultry - A review. Avian Pathology, v. 4, p. 1 $10,1975$.

YALÇIN, S.; SETTAR, P.; DICLE, O. Influence of dietary protein and sex on walking ability and bone parameters of broilers. British Poultry Science, v.39, n.2, p. 251 - 256, 1998.

ZUBAIR, A.K.; LEESON, S. Compensatory growth in the broiler chicken: a review. World 's Poultry Science Journal, v. 52, p. 189 - 201, 1996. 